\title{
Upside-down stomach - results of mini-invasive surgical therapy
}

\author{
Radek Vrba', Rene Aujesky ${ }^{1}$, Katherine Vomackova ${ }^{1}$, Lenka Zbrozkova ${ }^{2}$, Cestmir Neoral ${ }^{1}$ \\ ${ }_{1}^{1} 1^{\text {st }}$ Department of Surgery, Palacky University Medical School and Teaching Hospital Olomouc, Czech Republic \\ 2Department of Radiology, Palacky University Medical School and Teaching Hospital Olomouc, Czech Republic
}

Videosurgery and Other Miniinvasive Techniques 2011; 6 (4): 231-235

DOI: 10.5114/wiitm.2011.26257

\begin{abstract}
Aim: The authors evaluate the results of mini-invasive therapy in patients diagnosed with upside-down stomach.

Material and methods: From 1998 to 2008, a total of 27 patients diagnosed with upside-down stomach were surgically treated at the $1^{\text {st }}$ Department of Surgery, University Hospital Olomouc. Before the operation, patients were examined endoscopically and a barium swallow was performed. In all 27 patients (100\%), the operation was performed electively laparoscopically. The principle of the operation in all cases was reposition of the stomach into the abdominal cavity, resection of the hernial sac and hiatoplasty. In addition, in 15 patients (56\%) with reflux symptoms or endoscopic findings of reflux oesophagitis, fundoplication in Nissen's modification was also performed. Fundopexy was indicated in 12 patients (44\%).

Results: In all patients (100\%), the operation was performed mini-invasively; conversion to an open procedure was never necessary. In 3 cases (11\%), the left pleural cavity was opened during the operation; this was treated by introducing a chest drain. The operation mortality in the patient set was zero; morbidity was $11 \%$. A year after the operation, patients were re-examined, and follow-up endoscopy and barium swallow were performed.

Conclusions: In all patients diagnosed with upside-down stomach, surgical treatment is indicated due to the risk of developing severe complications. Mini-invasive surgical therapy in the hands of an experienced surgeon is a safe procedure which offers patients all the benefits of mini-invasive therapy with promising short-and long-term results.
\end{abstract}

Key words: upside-down stomach, mini-invasive surgical therapy, complications of therapy.

\section{Introduction}

Upside-down stomach is an extreme form of paraoesophageal hiatal hernia where the entire stomach is dislocated into the thoracic cavity [1, 2]. Other abdominal organs may be present in the large hernial sac, most often the spleen or part of the large intestine [3]. In patients diagnosed with upside-down stomach, there is a high risk of developing severe complications, which may have a fatal outcome for the patient. Surgical treatment is the only curative therapy and at the same time prevents the development of complications.
Our work presents elective surgical laparoscopic therapy in a set of patients diagnosed with upsidedown stomach. Over a period of 10 years, perioperative and postoperative results were retrospectively evaluated, and one year following the operation, long-term results of surgical therapy were evaluated.

\section{Material and methods}

From 1998 to 2008, a total of 27 patients diagnosed with upside-down stomach were surgically treated at the $1^{\text {st }}$ Department of Surgery, University Hospital Olomouc. The patient set included only 
patients with a chronic course of the disease and where the entire stomach was localized in the mediastinum, based on the X-ray barium swallow. The patient set consisted of 16 males (60\%) and 11 females (40\%). The age of the patients ranged from 43 years to 77 years; the average age was 63 years. The reported duration of symptoms ranged from 7 months to 4 years; the average duration was 26 months. Dominating symptoms included postprandial chest pressure and breathlessness, which were described in 21 cases (77\%). Typical symptoms of oesophageal reflux disease such as pyrosis, epigastric pain and regurgitation, along with the aforementioned symptoms, were present in 11 patients (40\%).

Diagnosis of the disease was based on endoscopic examination and barium swallow (Figure 1). To exclude a cardiac aetiology of chest pain, a cardiologic examination was performed.

Patients were operated on under general endotracheal anaesthesia. Patients were placed in a supine, anti-Trendelenburg position with abducted lower limbs. The operator stood between the lower limbs of the patient, first assistance to the left and second assistance to the right. Capnoperitoneum

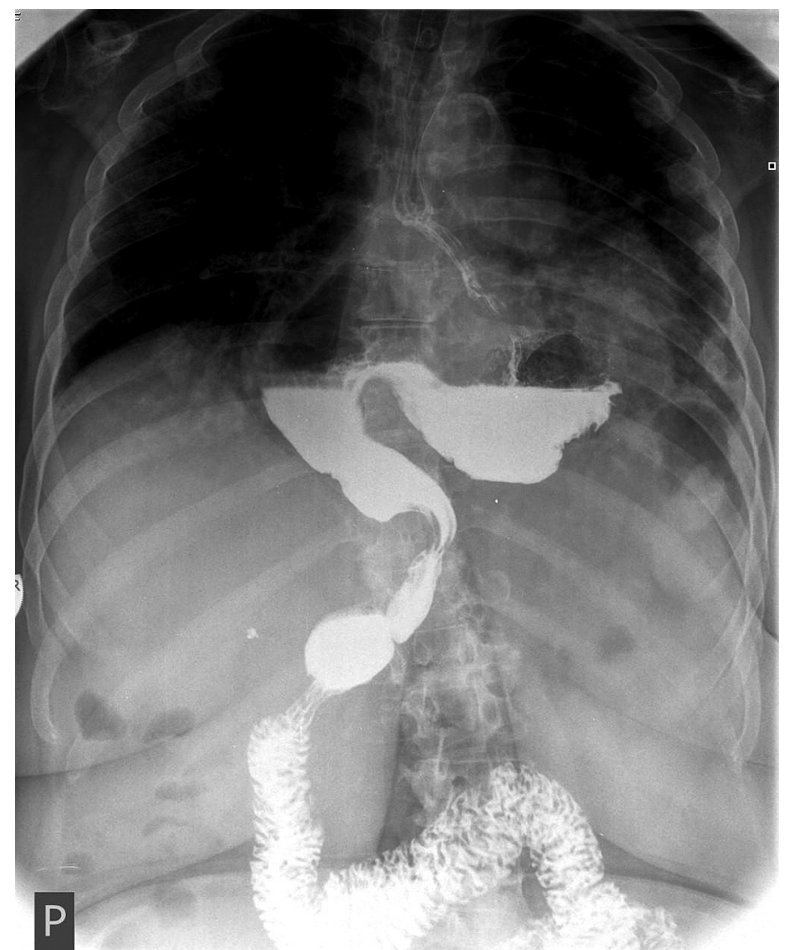

Figure 1. Barium swallow: image of upside-down stomach was introduced by way of a Veress needle; during the operation the pressure was set to $10 \mathrm{mmHg}$ with a maximum of $12 \mathrm{mmHg}$. The operation was performed from five entries; the standard four $10 \mathrm{~mm}$ ports and one $5 \mathrm{~mm}$ port were used. A port introduced $10 \mathrm{~cm}$ below the xiphoid process was used to introduce the laparoscope with 30-degree optics. The operator used a $10 \mathrm{~mm}$ port left of the middle axial line, using the right hand to operate the dissector with monopolar coagulation, scissors and harmonic scalpel. The left hand worked with the Endoclinch in a $5 \mathrm{~mm}$ port, which was located below the right ribcage $5 \mathrm{~cm}$ from the linea alba. Another $10 \mathrm{~mm}$ port was introduced below the xiphoid process for the liver retractor to elevate the left liver lobe. The last $10 \mathrm{~mm}$ port was introduced below the left ribcage in the anterior axial line for the atraumatic Babcock. After introduction of the instruments, careful reposition of the stomach from the mediastinum back into the abdominal cavity was performed (Figure 2). Discision of the pars flaccida of the lesser omentum using the harmonic scalpel with interruption of the Leimer membrane followed. The next step included resection of the large hernial sac, which in some patients was difficult due to adherence to the parietal pleura. A nasogastric tube was always introduced into the stomach by the anaesthesiologist for better orientation of the oesophagus position and to prevent its injury. After isolation of the right and left crus of the diaphragm, the distal oesophagus was mobilized approximately $6 \mathrm{~cm}$ above the cardia (Figure 3). A Collis gastroplasty for short oesophagus was never per-

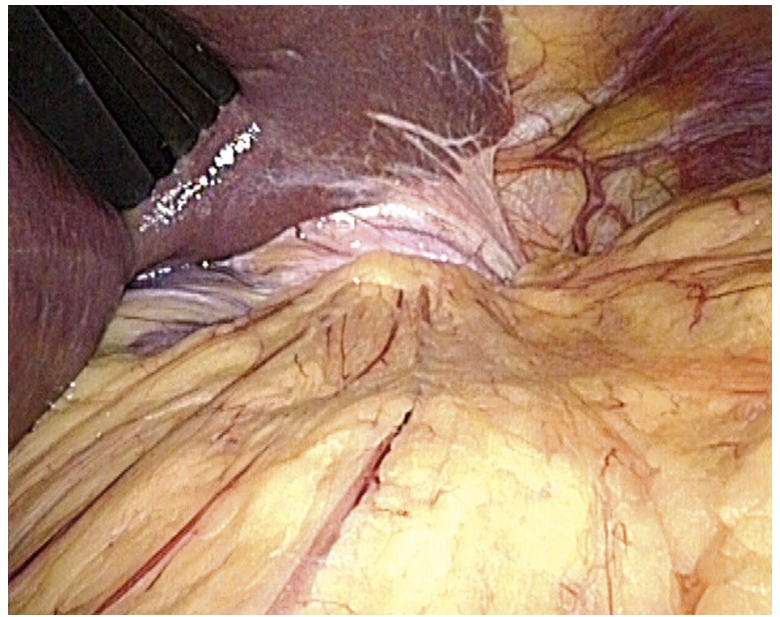

Figure 2. Laparoscopic image of the abdominal cavity in patients with upside-down stomach 
formed; in all cases, it was possible to sufficiently mobilize the oesophagus below the diaphragm. The hiatoplasty was performed in all patients by individual Z stitches using the Endostitch with suture strength 0; on average 3 stitches were used. During construction of the hiatoplasty, a calibration probe of $42 \mathrm{~F}$ was introduced into the stomach. In 12 patients (44\%) without reflux symptomatology, a fundopexy by three individual $U$ stitches to the ventral peritoneum with suture strength 0 was performed. In 15 patients (56\%) with reported reflux symptoms or with endoscopic findings of reflux oesophagitis a Nissen fundoplication was indicated. Construction of the fundoplication was done using four individual stitches with Endostitch 2-0 suture material. The last stitch was fixed to the distal oesophagus to prevent the telescopic phenomenon. Drainage was introduced individually in 13 patients (48\%) based on blood loss during the operating procedure.

\section{Results}

In all 27 patients (100\%) the operation was performed laparoscopically; conversion to a classical operation from laparotomy was never necessary. All the patients were operated on by surgeons with many years' experience in mini-invasive surgical treatment of oesophageal reflux disease. The average operation time was 135 min; the range in operation time was 107 min to 182 min. In 3 cases (11\%), during preparation of the stomach in the mediastinum, the left thoracic cavity was iatrogenically opened with development of pneumothorax, which was treated by chest drainage. No other severe perioperative complication was seen. Blood loss during the procedure ranged from $20 \mathrm{ml}$ to $85 \mathrm{ml}$; the average was $51 \mathrm{ml}$. Drainage of the abdominal cavity was removed on the $2^{\text {nd }}$ postoperative day at the latest; the secretion never surpassed $50 \mathrm{ml}$. Postoperative pain was treated by analgesic therapy. No serious complications were observed immediately following the operation. Mortality in our set of patients was zero, morbidity $11 \%$. On average, patients were released from the surgery department into the care of their general practitioners 5.4 days postoperatively.

To evaluate long-term results of the surgical treatment, patients were invited for follow-up one year following the operation. A total of 21 patients (77\%) attended the follow-up. Upon endoscopy and barium swallow, no patients showed recurrence of hiatal her-

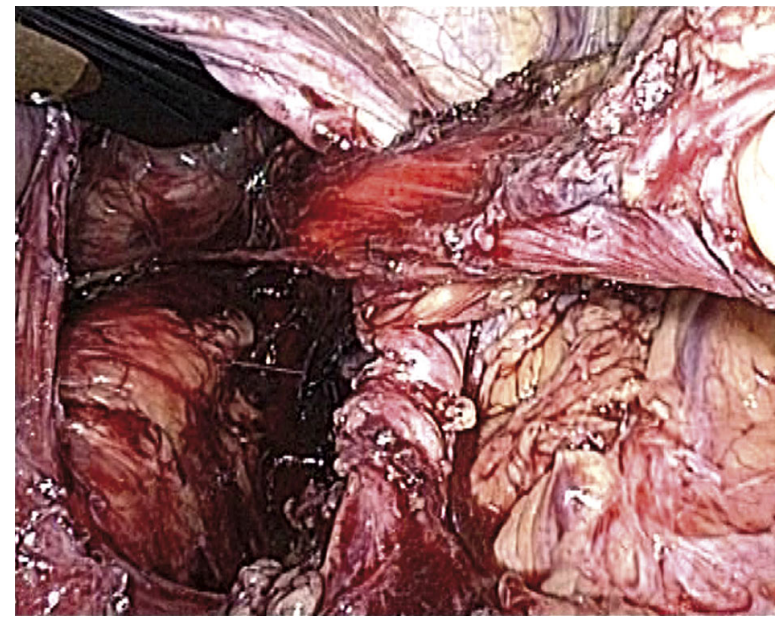

Figure 3. Dissected diaphragmatic crus with the distal oesophagus prior to hiatoplasty and fundoplication

nia or other pathology of the oesophagus or stomach. Subjectively, 16 patients (76\%) evaluated their condition as very favourable, without presence of preoperative symptoms or other problems. In 2 patients (9\%), minimal intermittent dysphagia without weight loss was present. Three patients (14\%) reported postprandial dyspepsia; after administration of prokinetics their condition partially improved. In 1 case (4\%), dislocation of the fundoplication into the mediastinum occurred 17 months following the operation, which was confirmed endoscopically and by barium swallow. Reoperation was performed in this patient laparoscopically; the fundoplication was repositioned back into the abdominal cavity with a new hiatoplasty.

Table I. Results of surgical therapy in patients diagnosed with upside-down stomach

\begin{tabular}{|ll|}
\hline Patients & $(n=27)$ \\
\hline Sex (males : females) & $16(60 \%): 11(40 \%)$ \\
\hline Mini-invasive procedure & $27(100 \%)$ \\
\hline Average operation time & 135 min \\
\hline Morbidity & $\begin{array}{l}3(11 \%)-\text { left-sided } \\
\text { pneumothorax }\end{array}$ \\
\hline Mortality & 0 \\
\hline Reoperation & $1(4 \%)-$ hernia recurrence \\
\hline
\end{tabular}




\section{Discussion}

Upside-down stomach is an extreme form of hiatal hernia with organoaxial torsion of the stomach and its localization in the thoracic cavity; the hernial sac may also contain other abdominal organs [4]. The diagnosis of upside-down stomach was first described by Berti during autopsy in 1866, the first mention of surgical therapy in 1896 by Berg [5].

Major symptoms of the disease include postprandial chest discomfort, breathlessness, dysphagia, vomiting and anaemia [5]. Typical symptoms of oesophageal reflux disease may not be present [6]. In most cases, the course of the disease is chronic. It is manifested acutely in case of complications, which include strangulation, stomach obstruction, and acute bleeding from ulceration [3, 7]. Strangulation may even lead to stomach gangrene with subsequent perforation and the development of mediastinitis. In cases of obstruction, aspiration of stomach contents into the respiratory tract may occur $[4,8]$. All of these cases are severe complications, which if not diagnosed in time and immediately treated may be life-threatening for the patient $[4,9]$.

Diagnosis is established based on X-ray examination (barium swallow) and endoscopic examination. The radiological image shows the entire stomach in the chest and the GE junction is in close proximity to the oesophageal hiatus [3].

All patients with upside-down stomach are indicated for surgical treatment $[1,3]$. In patients with acute symptoms of the disease, an urgent surgical procedure is indicated; the type of procedure is modified based on perioperative findings $[3,7,10]$. In the remaining patients, an elective procedure is performed. Laparoscopic operation of paraoesophageal hernia was first described by Cushieri in 1992 [5]. Works published in the last decade regarding large paraoesophageal hernias clearly prefer the elective mini-invasive surgical approach [5, 8, 11, 12]. Works published in the last three years mention using the robotic system during operations of paraoesophageal hernias. Hartman reports on operations of upsidedown stomach using the Da Vinci robotic system. Oesophageal preparation around the hiatus is considered to be the primary advantage; the cost of the procedure and educating time of the operation team are disadvantages [13]. Individual authors all agree on the principle of the surgical procedure (stomach reposition back into the abdominal cavity, resection of the hernia sac, hiatoplasty and fundoplication) $[6,11,14$, 15]. A short oesophagus may present a problem, and is defined as being at least $5 \mathrm{~cm}$ distant from the GE junction above the diaphragm. Swanstrom reports this finding in $14 \%$ of patients, and in $30 \%$ of these patients the oesophagus was mobilized laparoscopically without complications. In the remaining cases where the oesophagus could not be mobilized, a Collis gastroplasty was performed, where $20-70 \%$ of patients report its benefit in minimal incidence of postoperative dysphagia, acid reflux to the oesophagus and hernia recurrence [16]. The literature reports performance of a Collis gastroplasty for short oesophagus ranging from 0\% (Ponsky) to 20\% (Yano) $[11,12,17]$. In our set of patients, it was always possible to mobilize the distal oesophagus to a sufficient extent with placement of the GE junction below the diaphragm. Hiatoplasty is always part of the surgical procedure. Gantert prefers its performance without using a mesh, while Zehetner and Oelschlanger report a lower percentage of hernia recurrence after implantation of a mesh into the oesophageal hiatus $[1,14,18]$. In our set of patients, hiatoplasty was performed using individual cross stitches with Endostitch. Fundoplication is included in the procedure for low percentage of hernia recurrence and optimal prevention of acid reflux into the oesophagus in the postoperative period [19]. In over $90 \%$ of cases, fundoplication is performed in the Nissen modification $[4,6,12,20]$. Other presented possibilities include Toupet or Dorr plasty [5, 8, 20]. Gastropexy is reported as another possibility to prevent hiatal hernia recurrence $[7,21]$. In our set of patients, we preferred gastropexy in patients without reflux symptomatology with a promising endoscopic finding without reflux oesophagitis. Perioperative complications of mini-invasive therapy for upside-down stomach are comparable to the incidence of complications in patients operated for gastroesophageal reflux disease (bleeding, injury to the liver, spleen, stomach and oesophagus). Operation conversion is most often due to injury to the oesophagus, bleeding, or unclear operating field $[1,5,12,22]$. When comparing with results of patients with other types of hiatal hernia, there is a higher incidence of injury to the pleura and opening of the thoracic cavity with development of pneumothorax during preparation of the large hernial sac [5, 23]. In terms of long-term results, the most common complication is hernia recurrence, which in large patient sets is reported as being up to 
$10 \%[11,14,21]$. Reoperations are indicated for symptomatic hernia recurrence or return of reflux symptoms; Gantert and Andujar report a rate of $4 \%$ to $6 \%$ $[11,14]$.

\section{Conclusions}

Surgical treatment is the only curative therapy in patients with upside-down stomach. Operation is preferred even in patients with minimal symptoms of the disease to prevent the development of serious complications of the disease. An elective laparoscopic operation in the hands of an experienced surgeon is a safe procedure which brings the patient all the benefits of a minimally invasive procedure with a minimal number of perioperative and postoperative complications and promising long-term results [24-27].

\section{References}

1. Zehetner J, Lipham JC, Ayazi S, et al. A simplifield technique for intrathoracic stomach repair: laparoscopic fundoplication with Vicryl mesh and BioGlue crural reinforcement. Surg Endosc 2010; 24: 675-9.

2. Šerý Z, Králík J. Příspěvky k anatomii, histologii, fyziologii hiátové části bránice. Frenoesofageální membrána. Acta Palack Olomouc 1956; 11: 257-61.

3. Cherukupalli C, Khaneja S, Bankulla P, Schein M. CT diagnosis of acute gastric volvulus. Die Surg 2003; 20: 497-9.

4. Katkhouda N, Mavor E, Achanta K, et al. Laparoscopic repair of chronic intrathoracic gastric volvulus. Surgery 2000; 128 784-90.

5. Yano F, Stadlhuber RJ, Tsuboi K, et al. Outcomes of surgical treatment of intrathoracic stomach. Dis Esophagus 2009; 22: 284-8.

6. Krahenbuhl L, Schafer M, Farhadi, et al. Laparoscopic treatment of large paraesophageal hernia with totally intrathoracic stomach. J AM Coll Surg 1998; 187: 231-7.

7. Ekelund M, Ribbe E, Willner J, Zilling T. Perfored peptic ulcer in paraesophageal hernia - a case report of a rare surgical emergency. BMC Surg 2006; 6: 1

8. Athanasakis H, Tzortzinis A, Tsiaoussis J, et al. Laparoscopic repair of paraesophageal hernia. Endoscopy 2001; 33: 590-4.

9. Duda M, Dlouhý M, Gryga A, et al. Langzeitige Beobachtung der webem paraosophagealen und gemischten Hiatushernien operierten Krankem. Erfahrungen mit mehr als 100 Operierten. Zent Bli Chir 1991; 116: 729-36.

10. Rapant V. K strategii chirurgického výkonu po druhotných komplikacích hiátových kýl. Acta Univ Olomouc Fac Med 1961; 23: 253-56.

11. Andujar JJ, Papasavas PK, Birdas T, et al. Laparoscopic repair of large paraesophageal hernia is associated with low incidence of recurrence and reoperation. Surg Endosc 2004; 18: 444-7.

12. Wiechmann RJ, Ferguson MK, Naunheim KS, et al. Laparoscopic managment of giant paraesophageal herniation. Ann Thorac Surg 2001; 71: 1080-6.
13. Hartmann J, Jacobi CA, Menenakos C, et al. Surgical treatment of gastroesophageal reflux disease and upside-dowm stomach using the Da Vinci robotic system. A prospective study. J Gastrointest Surg 2008; 12: 504-9.

14. Gantert WA, Patti MG, Arcerito M, et al. Laparoscopic repair of paraesophageal hiatal hernias. J Am Coll Surg 1998; 186: 428-32.

15. Migaczewski M, Budzynski A, Rembiasz K, Choruz R. Quality of life of patients with gastroesophageal reflux disease after laparoscopic Nissen fundoplication. Videosurgery and Other Miniinvasive Techniques 2008; 3: 119-25.

16. Swanstrom LL, Marcus DR, Gallowa GQ. Laparoscopic Collis gastroplasty is treatment of choise for the shortened esophagus. Am J Surg 1996; 171: 477-81.

17. Ponsky J, Rosen M, Fanning A, Malm J. Anterior gastropexy may reduce reccurence rate after laparoscopic paraesophageal hernia repair. Surg Endosc 2003; 17: 1036-41.

18. Oelschlanger BK, Pellegrini CA, Hunter J, et al. Biologic prosthesis reduced recurrence after laparoscopic paraesophageal hernia repair: a multicenter, prospective, randomized trial. Ann Surg 2006; 244: 481-90.

19. Neoral C, Král V. Laparoscopic fundoplication. Rozhl Chir 1996; 7: 345-8.

20. Livingston CD, Jones HL Jr, Askew RE Jr, et al. Laparoscopic hiatal hernia repair in patients with poor esophageal motility or paraesophageal herniation. Am Surg 2001; 67: 987-91.

21. Boushey RP, Moloo H, Burpee S, et al. Laparoscopic repair of paraesophageal hernias: a Canadian experience. Can J Surg 2008; 51: 355-60.

22. Rembiasz K, Bobrzynski A, Budzynski A, et al.Analysis of complications of laparoscopic management of abdominal disease related to extended indications. Videosurgery and Other Miniinvasive Techniques 2010; 5: 53-9.

23. Hohmann U, Jahnichen A, Schramm H. The upside-down stomach. Laparoscopic treatment is possible. Zentrlbl Chir 2001; 125: 394-7.

24. Stylopoulos N, Gazelle GS, Rattner DW. Paraesophageal hernias: operation or observation? Ann Surg 2002; 236: 492-500.

25. Edye MB, Canin-Endres J, Gattorno F, Salky BA. Durability of laparoscopic repair of large type III hiatal hernia: objective follow up reveals high recurrence rate. J Am Col Surg 2000; 190: 553-60.

26. Mattar SG, Bowers SP, Galloway KD, et al. Long-term outcome of laparoscopic repair of paraesophageal hernia. Surg Endosc 2002; 16: 745-9.

27. Huntington TR, Short-term outcome of laparoscopic paraesophageal hernia repair. A case series of 58 consecutive patients. Surg Endosc 1997; 11: 894-8. 